\title{
Letter to the Editor: A call for more complete reporting and evaluation of experimental methods, physical forms of starters, and results in calf research
}

A. F. Kertz ${ }^{1}$

ANDHIL LLC, St. Louis, MO 63122-1915
A 5-yr review of published calf and heifer studies (Kertz and Chester-Jones, 2004) found basic information not being provided, too few animals being studied per treatment, and even failure to report sex of the calves. Calf and heifer experimental reporting guidelines were recommended in that review. Unfortunately, many calf studies still do not report basic information about the feeding program and resulting performance. Some basic information not reported includes level of milk replacer solids mixed, composition of milk or milk replacers fed, feeding times, physical form and CP level of calf starter fed, and season of year (ambient temperature would be even better). On the other hand, a good example of rather complete protocol information is found in a recent study by Hill et al. (2015).

Since the review by Kertz and Chester-Jones (2004), physical form of starter has come to the forefront, beginning with the report of Porter et al. (2007), in which the texturized form of starter resulted in greater calf starter intake, ADG, and improved rumen parameters compared with a pelleted starter. But not all studies with texturized starters exhibited the same increased calf performance. Experiment 2 in Terré et al. (2015) found greater BW $(P<0.05)$ at weaning (d 52 of age) for pelleted starter and straw compared with pelleted starter alone or texturized starter. Data were included on particle size distribution of the straw but not of the starters. Wet sieving may also be appropriate for pellets. But starter intake (0.51 to $0.60 \mathrm{~kg} /$ calf daily), $\mathrm{ADG}$ (0.34 to $0.40 \mathrm{~kg} /$ calf daily), and intake (0.44 $\mathrm{kg} / \mathrm{d}$ ) of milk replacer containing $23 \% \mathrm{CP}$ with $19.5 \%$ fat milk replacer were quite low across all treatments. By contrast, in experiment 1 of Terré et al. (2015), calves had ADG of 0.61 to 0.70 with starter intakes of 0.26 to $0.32 \mathrm{~kg}$, and intake of whole milk solids of $0.82 \mathrm{~kg}$ daily. Results in experiment 2 were unusual and limited the ability to determine more significant differences in performance among treatments. No measures

Received July 6, 2016.

Accepted October 20, 2016.

${ }^{1}$ Corresponding author: andhil@swbell.net of height, frame size, or gut fill were provide in experiment 2. In full disclosure, I contributed to the design of the experiment and the starter treatments but opted not to be included as a coauthor.

Another study by Khan et al. (2011) appeared to show that hay improved calf performance when provided in addition to what was described as a texturized starter containing, on an as-fed basis, $57.5 \%$ concentrate pellet, $14 \%$ flatted barley, $13 \%$ flatted oats, $10 \%$ steamed corn, and 3.5\% molasses. But the rumen $\mathrm{pH}$ at slaughter of male Holstein calves at d 70 age was only 5.06 for the texturized starter versus $5.49(P<0.05)$ when chopped orchard grass hay was also provided in addition to starter. This indicates that the levels of processed grains did not provide adequate texture, and had no real benefit (Lesmeister and Heinrichs, 2004; Bateman et al., 2009) has been found to processing corn. Another key result was not acknowledged by Khan et al. (2011). Although BW were the same for both treatments at sacrifice, reticulo-rumen fill was $69 \%$ greater on the supplemental hay treatment. That means that true BW was actually $4.4 \mathrm{~kg}$ less after accounting for the difference in gut fill. Unfortunately, measures of gut fill have not been made in several studies in which hay was also fed. Gut fill is a confounding factor that distorts true BW gain. For example, in the trials by Coverdale et al. (2004), there were no measures of height, frame size, or gut fill, but BW and feed efficiency were greater with hay treatments. The classical study of Stobo et al. (1966) also supports the need to have a wider range of dietary forage to delineate at what point gut fill becomes a more significant negative factor.

Other factors also affect DMI, ADG, and overall performance of preweaned calves (Kertz and Loften, 2013). Examples are amount of milk or milk replacer fed, solids level, protein and fat levels, and weaning transition process. If a study lacks a good critical literature review, both within and outside networks of authors, their studies, and literature contrary to their viewpoints, then these issues are not included and addressed. In the recent review by Khan et al. (2016), 14 
places were identified in the review where the effect of physical form of starter was not adequately addressed. This was addressed in a personal discussion with an author and further in email exchanges.

Just as particle size distribution is commonly quantified in TMR formulations for dairy cows, particle sizes in textured calf starters should be measured, starter physical forms identified, and forages quantified by nutrient content and particle size. And in preparing manuscripts in which other calf studies are cited, the physical form of starters must be characterized in each of those cited studies because physical form affects DMI, ADG, and potentially gut fill. Otherwise, the literature will be further confounded by not providing this significant comparative information.

\section{REFERENCES}

Bateman, H. G., II, T. M. Hill, J. M. Aldrich, and R. L. Schlotterbeck. 2009. Effects of corn processing, particle size, and diet form on performance of calves in bedded pens. J. Dairy Sci. 92:782-789.

Coverdale, J. A., H. D. Tyler, J. D. Quigley III, and J. A. Brumm. 2004. Effect of various levels of forage and form of diet on rumen development and growth in calves. J. Dairy Sci. 87:2554-2562.
Hill, T. M., H. G. Bateman II, J. M. Aldrich, J. D. Quigley, and R. L. Schlotterbeck. 2015. Inclusion of tallow and soybean oil to calf starters fed to dairy calves from birth to four months of age on calf performance and digestion. J. Dairy Sci. 98:4882-4888.

Kertz, A. F., and H. Chester-Jones. 2004. Guidelines for measuring and reporting calf and heifer experimental data. J. Dairy Sci. $87: 3577-3580$

Kertz, A. F., and J. R. Loften. 2013. A historical perspective and brief review: Holstein dairy calf milk replacer feeding programs in the U.S. Prof. Anim. Sci. 29:321-332.

Khan, M. A., A. Bach, D. M. Weary, and M. A. G. von Keyserlingk. 2016. Invited review: Transitioning from milk to solid feed in dairy heifers. J. Dairy Sci. 99:885-902.

Khan, M. A., D. M. Weary, and M. A. G. von Keyserlingk. 2011. Hay intake improves performance and rumen development of calves fed higher quantities of milk. J. Dairy Sci. 94:3547-3553.

Lesmeister, K. E., and A. J. Heinrichs. 2004. Effects of corn processing on growth characteristics, rumen development, and rumen parameters in neonatal dairy calves. J. Dairy Sci. 87:3439-3450.

Porter, J. C., R. G. Warner, and A. F. Kertz. 2007. Effect of fiber level and physical form of starter on growth and development of dairy calves fed no forage. Prof. Anim. Sci. 23:395-400.

Stobo, I. J. F., J. H. B. Roy, and H. J. Gaston. 1966. Rumen development in the calf. 1. The effect of diets containing different proportions of concentrates to hay on rumen development. Br. J. Nutr. 20:171-188

Terré, M., Ll. Castells, M. A. Khan, and A. Bach. 2015. Interaction between the physical form of the starter feed and straw provision on growth performance of Holstein calves. J. Dairy Sci. 98:1101-1109. 